The labours of the Poor-law committee of the Provincial Association are highly praiseworthy; may they be the means of producing an alteration in the present state of things more advantageous and satisfactory to all parties concerned.

Your obedient servant,

\section{E. Copeman.}

Coltishall, near Norwich, August 3, 1841.

CASE OF IMPERFORATE ANUS, WITH ABSENCE OF THE RECTUM, IN WHICH THE COLON OPENED INTO THE SUPERIOR FUNDUS OF THE BLA DDER. - BY M. DUBREUILH.

On the 9th of February, a woman was delivered when $7 \frac{1}{2}$ months pregnant. The child, which laboured under imperforate anus and phimosis, readily drank some sugar and water. On the 10th, no urine had been passed-the abdomen was tense - some greenish matter was vomited, unmixed with anything resembling meconium. In the evening a few drops of milky fluid escaped from the urethra. In the situation where the anus should have existed, a soft point, with some sense of fluctuation, was detected; and on the 11 th, an incision was made in this situation to the depth of twelve millimetres; but the bottom of the wound, when examined, afforded everywhere a hard, resisting sensation, and no focal matter, whether solid or fluid, found exit. In the evening there was a copious flow of transparent urine; and, on the morning of the 12th, the prepuce was found covered with a greenish matter, which was recognised as the meconium; whence it was concluded that the great intestine communicated with the bladder, in what situation, however, could not be determined. On withdrawing a tent of lint from the wound in the perineum, a few bubbles of gas escaped, which led to the hope that the rectum had been opened; prepared sponge was placed in the wound with the view of dilating it.

The following days the child vomited frequently, and the abdomen became distended; the distension, however, occasionally becoming diminished; the urine was clear and limpid: but some meconium daily passed away by the urethra. On the 19th the child died, having thus lived ten days.

\section{Post-mortem examination.}

The abdomen was tense; the peritoneum, epiploon, and intestines were red, and the convolutions of the latter adhered to each other by means of false membranes. On following the colon, it was found that the rectum was altogether deficient; while the colon, running exactly along the linea alba, terminated in the summit of the bladder, which was about the size of a hen-egg. A probe passed along the urethra entered the colon through the bladder; the opening between the bladder and colon was 12 millimetres in diameter. The bladder was full of yellow focal matter; its mucous membrane was of a reddish brown colour, and its parietes two millimetres in thickness. The ureters could not be discovered; the urethra was natural : the parietes of the colon, in the vicinity of, and for some distance above the bladder, were thin and transparent, but of natural thickness in the rest of their extent.-Journal de la Société de Med. de Bourdeaux and Med. Press.
ARTIFICIAL ABORTION IN A CASE OF EXTRAUTERINE PREgNANCY.-BY PROFESSOR RITGEN.

A woman, aged 32, May, 1834, was attacked with vomiting and pain in the abdomen, especially at the right side corresponding to the ovary, in which situation a tumor was soon perceived; at first the size of an orange, it, in six weeks, attained the size of an infant's head. 'The pain extended to the back down the right thigh, and daily augmented, so that the patient was finally deprived of sleep; she was frequently constipated, and there was fever, thirst, subsequently jaundice, and, at length, slight anasarca. M. Ritgen saw the patient on the $42 \mathrm{~d}$ day of her illness, and learned that she was large and/well made, and had already borne three children without the slightest accident.

The woman considered herself pregnant from the menses being suppressed for eleven weeks, and from other symptoms similar to those which she had previously experienced. The tumor was so large that it could not be covered with the open hand ; the pain was augmented by slight, dispelled by firm, pressure. The right side of the face was more odematous than the left; the right pupil was contracted, and the entire right eye seemed smaller than the opposite one; there was a general and decided sensation of uneasiness throughout the entire right side of the body. The liver appeared to be in a natural condition. The pulse was frequent-the skin hot and dry-thirst considerable-a yellow coating on the tongue-no appetite. On examination per vaginam, the orifice of the uterus was found on the left side; the inferior fundus of the organ was but little developed : and in the cul de sac of the vagina, on the right side, could be felt a tumor situated rather high up above the uterus, and which manifestly changed its position when the tumor in the right groin was moved. The fing $\mathrm{c} r$ being introduced into the rectum, the tumor was equally felt, situated at the right side above the uterus, which latter organ was but little increased in size. No discharge had occurred from the vagina for the space of three months. There had been constipation for twelve days, and the transverse colon could be traced beneath the integuments. These symptoms led to the conclusion that there was a fœus in the Fallopian tube-a diagnosis which was confirmed by auscultation affording a bruit de soufflet isochronous with the pulsations of the heart. 'The tumor seemed disposed to open, and was covered with narcotic cataplasms, and a seton inserted in its vicinity. With a view of producing absorption, sulphate of soda was given in an oily emulsion, and subsequently pills of ergot of rye, and watery extract of aloes, were administered. In twenty-four hours the pain in the tumor disappeared, and, on the third day, the patient was able to sleep. The pills at first caused vomiting; but, after some time, contractions commenced in the tumor and uterus; a sanguineous discharge appeared from the vagina, and in twelve hours the bowels were opened. The sanguineous discharge augmented gradually, and at length clots of blood appeared, which, being carefully collected and washed, on the third day, some of them were found to contain flocculent fragments of a tissue similar to that of the caducous membrane, and subse- 
quently portions of the chorion were discovered; but no other indications of an embryo were detected. On the fourth day the tumor was considerably diminished in size, but did not completely disappear for a year and a half; and there was a discharge of blood constantly during nine months. The bruit de soufflet diminished the first few days, and vanished at the expiration of three weeks. The ergot of rye and aloes were continued only three days, the glauber salts for eight. The woman is now well, and has not again become pregnant.-Ibid.

\section{VEGETABLE ORIGIN OF TINEA.}

IN our last number we mentioned the discovery of the vegetable origin of tinea capitis, by $M$. Gruby. Since then, M. Gruby has examined the vegetable in various ways; when submitted to heat, it burns with a red flame, and gives out an odour of burned bread; in a solution of subcarbonate of potass it becomes more flexible, without undergoing any change of form; it is dissolved by the tincture of iodine, and coagulates or contracts when a drop of acetic acid is added. M. Gruby has succeeded in inoculating this mycoderma on cryptogamic plants, and has thus transmitted a disease from man to vegetables, but was successful only once in 76 experiments. He also attempted to inoculate tinea capitis, by placing the vegetable in an incision made on the arm, but this experiment failed.

\section{SUBCUTANEOUS OPERATION FOR HERNIA.}

M. Gueris has recently applied this method to a case of strangulated inguinal hernia; the hernia was congenital, and had been strangulated for three days : the usual means of reduction were employed without avail, and the tumor was beginning to inflame. M. Guerin divided the two rings, and the antero-superior wall of the canal underneath the skin, and immediately returned the hernia (epiploon) into the abdomen. Not the slightest symptom of inflammation occurred, and the patient was able to get up on the eighth day. -Gaz. Med.

\section{DEATH OF M. SANSON.}

WiTH great regret we have to announce the death of M. Sanson, professor of clinical surgery to the Faculty of Medicine at Paris, which took place on the Ist of August. M. Sanson was born at Paris, on the 24th of January, 1790; in 1805 he was elected externe at the Hôtel-dieu, and was soon chosen by Dupuytren as demonstrator; in 1813 he joined the "old guard," and from the sufferings which he underwent during the campaign in Saxony, aggravated by fatigue and labour at the battle of Waterloo, he became sub. ject to attacks of rheumatism, which continued during the rest of his life. After the abdication of the Emperor, M. Sanson returned to Paris, and devoted himself, exclusively, to the duties of his profession.

In 1825 he became one of the surgeons of the
Hotel-dieu; in 1836 was elected profensor of clinical surgery to the Faculty of Medicine.

As practitioner and professor, M. Sanson was one of the most solid ornaments of French surgery, and had his health permitted, might have aspired to fill the place even of a Dupuytren.

\section{ANTIDOTE TO THE ,SALTS OF COPPER,} By M. BENOIST.

Liquid albumen is generally administered as an antidote in cases of poisoning with the salts of copper, but it has this disadvantage, that, as we are unacquainted with the exact quantity necessary to neutralize the copper, if we employ too great a quantity, the poison is dissolved in the excess of albumen. To remedy this inconvenience M. Benoist proposes to substitute for albumen a solution of carbonate of soda, which forms. with the salts of copper an insoluble carbonate, having no deleterious action on the economy.Journ. de Chimie.

\section{TREATMENT OF TINEA CAPITIS.}

THE following "are the formula commonly employed by $M$. Casenave in the treatmeut of this disease at the hospital of St. Louis.

Ioduret of sulphur ointment.

Ioduret of sulphur, 1 scruple.

Lard, 30 scruples.

\section{Depilatory ointment.}

Subcarbonate of soda, 8 scruples.

Lime, 4 scruples.

Lard, 30 scruples.

Pitch ointment.

Citrine ointment, 15 scruples.

Pitch ointment, 30 scruples.

Or, powdered pepper, 2 to 4 scruples.

Lard, 30 scruples.

The ointment is applied every evening : in the morning the head is washed with the following lotion :

Subcarbonate of patash, 8 scruples.

Distilled water, 500 scruples.

Journal de Med. Prac.

\section{ROYAL COLLEGE OF SURGEONS IN LONDON.}

List of Gentlemen admitted Members on Friday, August 6, 1841.- Jonathan Wilson, Lawry John Monteith, Adam Gordon, William Augustus Loy, Joseph Walmsley, Charles M'Shane, James Atkin, Samuel Payne Chennell, Graham Lacon, Richard Dawson, Annerly Allcock.

Printed by Thomas Ibotson, of 105, St. Martin's Iane, in the Parish of St. Martin in the Fields, and Grorge JosiaH Palmer, of 80, Regent Square, in the Parish of Bt. Pancras, at their Office, No. 3, Bavoy-street, Btrand, in the Precinet of the Savoy; and published by JoHN WILliams Runsev, at his Residence, No.6, Wellington-street, Strand, in the Precinct of the Binvoy.-Eriday, Auguat 13, i841. 